\title{
Risk factors for implant failure: a retrospective study in an educational institution using GEE analyses
}

\section{Marcelo BORBA ${ }^{(a)}$ Daniel DELUIZ (b) Eduardo José Veras LOURENÇO ${ }^{(a)}$ Luciano OLIVEIRA(c) Patrícia Nivoloni TANNURE(a)}

(a) Universidade Veiga de Almeida - UVA, School of Dentistry, Rio de Janeiro, RJ, Brazil.

(b) Universidade Estadual do Rio de Janeiro - UERJ, School of Dentistry, Department of Periodontology, Rio de Janeiro, RJ, Brazil.

(c) Pontifícia Universidade Católica do Rio de Janerio - PUC-RJ, Department of Implantology, Rio de Janeiro, RJ, Brazil.

Declaration of Interests: The authors certify that they have no commercial or associative interest that represents a conflict of interest in connection with the manuscript.

\section{Corresponding Author:}

Marcelo Chaves Ururahy Borba

E-mail: marcelochavesborba@gmail.com

https://doi.org/10.1590/1807-3107BOR-2017.vol31.0069

Submitted: Oct 31, 2016

Accepted for publication: May 22, 2017

Last revision: June 07, 2017
Abstract: This study aimed to evaluate dental implant outcomes and to identify risk factors associated with implant failure over 12 years via dental records of patients attending an educational institution. Dental records of 202 patients receiving 774 dental implants from 2002 to 2014 were analyzed by adopting a more reliable statistical method to evaluate risk factors with patients as the unit [generalized estimating equation (GEE)]. Information regarding patient age at implantation, sex, use of tobacco, and history of systemic diseases was collected. Information about implant location in the arch region and implant length, diameter, and placement in a grafted area was evaluated after 2 years under load. Systemic and local risk factors for early and late implant failure were studied. A total of 18 patients experienced 25 implant failures, resulting in an overall survival rate of $96.8 \%(2.84 \%$ and $0.38 \%$ early and late implant failures, respectively). The patient-based survival rate was $91.8 \%$. GEE univariate and multivariate analyses revealed that a significant risk factor for implant failure was the maxillary implant $(p=0.006$ and $p=0.014$, respectively). Bone grafting appeared to be a risk factor for implant failure $(p=0.054)$. According to GEE analyses, maxillary implants had significantly worse outcomes in this population and were considered to be a risk factor for implant failure. Our results suggested that implants placed in a bone augmentation area had a tendency to fail.

Keywords: Dental Implants; Retrospective Studies; Survival Rate; Multivariate Analysis; Risk Factors

\section{Introduction}

Dental implants have been accepted as a viable treatment option for completely and partially edentulous patients..$^{1,2,3}$ Further improvements toward the successful osseointegration of dental implants have involved modifications to both surface topography and surface chemistry. ${ }^{4}$ Implant design (i.e., types and dimensions), surgical procedure, implant placement time, and time prior to loading have been shown to influence implant survival rates., ${ }^{5,6,78}$

Therefore, risk factors associated with implant failure have become a frequently discussed topic in recent dental research. Among patient factors, male gender, smoking, autoimmune disease, and penicillin allergy have been found to trend toward higher failure rates. ${ }^{9,10}$ In contrast, short implants in mandibular posterior sites have been found to have a survival 
rate of $100 \%$, while the same was not true for implants in the maxillary posterior position, wherein 6-mm implants had a survival rate of only $87 \%{ }^{9}$

Most survival study designs are longitudinal and retrospective with many years of follow-up. Their statistical methods use implant failure as the unit of analysis, without considering multiple implant failures in the same patient. Outcomes related to implants in a single patient must be more closely correlated than those in separate patients; ignoring these correlations could result in a bias in p-value computations. ${ }^{11,12,13}$

Therefore, in this retrospective study, we aimed to evaluate dental implant outcomes and to identify risk factors associated with implant failure over 12 years via dental records of patients attending an educational institution.

\section{Methodology}

This study was approved by the Ethics Committee of Veiga de Almeida University (UVA) (945.096).

\section{Study sample}

This cross-sectional study was conducted using the dental records of patients who were treated at the Institute of Dentistry of the Pontifícia Universidade Católica of Rio de Janeiro between 2002 and 2014. The inclusion criteria included patients who had received at least 1 dental implant and whose implants were loaded with prostheses immediately or later. Postgraduate students under the supervision of an attending faculty performed all implant placements. Patients with incomplete dental records were excluded.

No patients were excluded on the basis of systemic disease if it did not contraindicate dental implant surgery.

\section{Study variables}

The variables included demographic factors, clinical factors, and surgery-dependent factors. The full list of variables under analyses included the following: patient age at the time of implant placement categorized into $<65$ years and $\geq 65$ years ${ }^{14}$; gender; systemic disorders (diabetes, hypertension, syphilis, hepatitis, and HIV infection); smoking status (smokers or non-smokers); implant position (maxillary or mandibular); implant diameter (ranging from 3.3 to $5.0 \mathrm{~mm}$ ); implant length (short or long); and bone augmentation (with or without).

\section{Outcome measurements}

The outcome measurements of implants were as follows:

a. Implant failure

This included implant loss, mobility or removal in case of progressive marginal bone loss, severe peri-implant infection, or implant fracture. Implant failures were classified as a) early implant failure and b) late implant failure.

b. Early implant failure

Early implant failure was assessed before the acquisition of osseointegration, i.e., before the placement of provisional restorations. In cases of immediate loading, however, early implant failure was reported when it occurred before the first disconnection of the provisional restoration because it was considered that the operator would not disconnect the provisional restoration before osseointegration. ${ }^{11}$ c. Late implant failure

Late implant failure was assessed after the acquisition of osseointegration, i.e., after the placement of provisional restorations. In cases of immediate loading, late implant failure was reported when it occurred after the first disconnection of the provisional restoration. ${ }^{11}$

\section{Data analyses}

Descriptive statistics were performed; absolute and relative frequency distributions were calculated for qualitative variables, and means \pm standard deviations were calculated for quantitative variables.

The overall survival rates of implants were estimated by implant- and patient-based analyses. In the implant-based analysis, each inserted implant was considered as the analysis unit, whereas in the patient-based analysis, each patient was followed up until their first implant failed. ${ }^{15}$

Generalized estimating equation (GEE) analyses were performed with a forced entry method, and all predictors were entered initially. GEE analyses were chosen for the evaluation of risk factors for patients, avoiding the cluster effect present in the commonly used logistic regression models. GEE analyses use a 
patient instead of an implant as the statistical unit, considering that the same patient may receive several implants and eventually present the same risk factors. ${ }^{11}$

Both descriptive and quantitative data were recorded in individual charts for later analysis. SPSS software (SPSS 22.0; SPSS Inc., Chicago, IL, USA) was used for statistical analyses. The level of statistical significance was set at $p<0.05$.

\section{Results}

A total of 202 dental records of patients who received dental implants were analyzed over the 12-year study period. A total of 774 implants were included. The study comprised patients with a mean age of $54.2 \pm 10.5$ years; $59.2 \%$ of the patients were women. Most patients (92.6\%) were healthy, and only $13(1.6 \%)$ dental implants were placed in patients who reported tobacco use at the time of implant placement. The mean duration of the functional period was $8.44 \pm 5.5$ months.

Baseline information is shown in Table 1. The overall implant-based cumulative survival rate (CSR) was $96.8 \%$. In the patient-based analysis, the CSR was $91.8 \%$. A total of 25 implants failed during the observation period. None of these implants were placed in patients with systemic disorders $(n=58)$.

Table 2 shows the results of the regression analysis of the study sample using GEE analyses. When the mandible alone was used as the risk factor, the odds ratio (OR) for implant failure further increased ( $p=0.006, \mathrm{OR}=0.247,95 \%$ CI 0.091-0.667). When adjusted for other variables included in the multivariate analysis, the mandible was not associated with implant failure and was considered to be a protection factor. These results remained significant when adjusted for other variables $(p=0.002, O R=7.513$, $95 \%$ CI 2.100-26.884). There was no association between bone augmentation and implant failure in the univariate analysis $(\mathrm{p}=0.067, \mathrm{OR}=2.738,95 \% \mathrm{CI}$ $0.930-8.061)$. In the multivariate analysis, the results showed a trend toward this association when adjusted for other described variables $(p=0.054, O R=0.300$, 95\%CI 0.088-1.019) in Table 2.

Risk factors for early implant failure were analyzed considering only those for which the same association was found between maxillary sites and implant loss in the univariate and multivariate analyses $(p=0.019$ and $p=0.015$, respectively). The strong trend for bone augmentation and implant loss found in the present study was not observed for other variables using univariate and multivariate analyses $(\mathrm{p}=0.077$ and $\mathrm{p}=0.141$, respectively) (data not shown).

Considering implant diameters, no failures were observed in wide implants. The chi-square test was used to verify whether implant diameter was related to implant failure, and no association was observed ( $p>0.05$ ).

Table 1. Baseline information $(n=774)$.

\begin{tabular}{|c|c|}
\hline Demographic variables & Number of implants (\%) \\
\hline \multicolumn{2}{|l|}{ Age } \\
\hline$\geq 65$ years & $116(14.9)$ \\
\hline$<65$ years & $658(84.4)$ \\
\hline \multicolumn{2}{|l|}{ Gender } \\
\hline Male & $316(40.8)$ \\
\hline Female & $458(59.2)$ \\
\hline \multicolumn{2}{|l|}{ Systemic disorders } \\
\hline With & $58(7.5)$ \\
\hline Without & $716(92.5)$ \\
\hline \multicolumn{2}{|l|}{ Anatomic variables } \\
\hline \multicolumn{2}{|l|}{ Jaw } \\
\hline Maxilla & $392(50.6)$ \\
\hline Mandible & $382(49.4)$ \\
\hline \multicolumn{2}{|l|}{ Location } \\
\hline Anterior & $197(25.5)$ \\
\hline Posterior & $577(74.5)$ \\
\hline \multicolumn{2}{|l|}{ Implant-related variables } \\
\hline \multicolumn{2}{|l|}{ Length } \\
\hline 6-8.5 mm (short) & $53(6.8)$ \\
\hline 9-18 mm (long) & 721 (93.2) \\
\hline \multicolumn{2}{|l|}{ Diameter } \\
\hline 3.25-3.5 mm (narrow) & $104(13.4)$ \\
\hline $3.7-4.3 \mathrm{~mm}$ (regular) & $640(82.7)$ \\
\hline 4.5-5.5 mm (wide) & $30(3.9)$ \\
\hline \multicolumn{2}{|l|}{ Ancillary procedures } \\
\hline \multicolumn{2}{|l|}{ Bone augmentation } \\
\hline With & $178(23.0)$ \\
\hline Without & $596(77.0)$ \\
\hline
\end{tabular}

Note: A total of 774 dental implants were placed in 202 patients during the study period of 12 years. Data are presented as the number of implants (percentage). 
Considering early implant failure, 22 of the 774 implants in 15 patients were removed before provisional or final restorations were placed. Late implant failure analysis revealed that 3 implants failed during the functional period, the details of which are present in Table 3.

Table 2. Univariate and multivariate risk factor analyses for implant failure using GEE.

\begin{tabular}{lcccr}
\hline \multirow{2}{*}{ Variables } & \multicolumn{2}{c}{ Univariate analysis } & \multicolumn{2}{c}{ Multivariate analysis } \\
\cline { 2 - 5 } & $p$-value & OR $(95 \% \mathrm{Cl})$ & $p$-value & OR (95\%Cl) \\
\hline Age: $<65$ years & 0.731 & $0.767(0.170-3.461)$ & 0.805 & $1.198(0.285-5.044)$ \\
Gender: Male & 0.416 & $0.674(0.260-1.744)$ & 0.691 & $0.832(0.335-2.065)$ \\
Jaw: Maxilla & $0.006^{*}$ & $0.247(0.091-0.667)$ & $0.014^{*}$ & $0.259(0.088-0.760)$ \\
Location: Anterior & 0.254 & $0.549(0.196-1.537)$ & 0.096 & $0.429(0.158-1.163)$ \\
Implant length: Long & 0.822 & $0.840(0.184-3.843)$ & 0.308 & $0.402(0.070-2.318)$ \\
Bone augmentation: Yes & 0.067 & $2.738(0.930-8.061)$ & 0.054 & $0.300(0.088-1.019)$ \\
\hline
\end{tabular}

Note: The analyses were adjusted for age ( $\geq 65$ years as reference), gender (female as reference), jaw (mandible as reference), location (posterior as reference), length (short as reference), bone augmentation (without as reference), OR $(95 \% \mathrm{CI})=$ odds ratio, $95 \%$ confidence intervals.

Table 3. Implant failure analysis

\begin{tabular}{|c|c|c|c|c|c|c|c|c|c|}
\hline Patient & Gender & Age (years) & $\begin{array}{l}\text { Systemic } \\
\text { disorders }\end{array}$ & Site & $\begin{array}{l}\text { Implant } \\
\text { diameter }\end{array}$ & $\begin{array}{l}\text { Implant } \\
\text { length }\end{array}$ & $\begin{array}{c}\text { Bone } \\
\text { augmentation }\end{array}$ & $\begin{array}{l}\text { Implant } \\
\text { failure time } \\
\text { (months) }\end{array}$ & Failure type \\
\hline 1 & MALE & $\geq 65$ & $\mathrm{NO}$ & 14 & NARROW & LONG & WITHOUT & 3 & EARLY \\
\hline 2 & FEMALE & $<65$ & NO & 14 & REGULAR & LONG & WITHOUT & 2 & EARLY \\
\hline 3 & FEMALE & $<65$ & $\mathrm{NO}$ & 25 & REGULAR & LONG & WITH & 1 & EARLY \\
\hline 3 & FEMALE & $<65$ & $\mathrm{NO}$ & 44 & REGULAR & LONG & WITH & 5 & EARLY \\
\hline 4 & MALE & $<65$ & NO & 36 & REGULAR & LONG & WITHOUT & 2 & EARLY \\
\hline 5 & FEMALE & $<65$ & NO & 13 & REGULAR & LONG & WITHOUT & 3 & EARLY \\
\hline 5 & FEMALE & $<65$ & $\mathrm{NO}$ & 24 & REGULAR & LONG & WITHOUT & 3 & EARLY \\
\hline 6 & FEMALE & $<65$ & NO & 16 & REGULAR & LONG & WITH & 11 & EARLY \\
\hline 6 & FEMALE & $<65$ & $\mathrm{NO}$ & 17 & REGULAR & LONG & WITH & 11 & EARLY \\
\hline 7 & FEMALE & $<65$ & $\mathrm{NO}$ & 26 & REGULAR & LONG & WITHOUT & 3 & EARLY \\
\hline 8 & MALE & $<65$ & $\mathrm{NO}$ & 36 & REGULAR & LONG & WITH & 5 & EARLY \\
\hline 9 & FEMALE & $<65$ & $\mathrm{NO}$ & 25 & NARROW & LONG & WITHOUT & 2 & EARLY \\
\hline 10 & MALE & $<65$ & NO & 11 & REGULAR & LONG & WITHOUT & 4 & EARLY \\
\hline 11 & MALE & $<65$ & $\mathrm{NO}$ & 16 & REGULAR & LONG & WITHOUT & 1 & EARLY \\
\hline 12 & MALE & $<65$ & $\mathrm{NO}$ & 15 & NARROW & LONG & WITHOUT & 10 & EARLY \\
\hline 13 & FEMALE & $<65$ & $\mathrm{NO}$ & 16 & NARROW & LONG & WITH & 8 & EARLY \\
\hline 13 & FEMALE & $<65$ & $\mathrm{NO}$ & 24 & NARROW & LONG & WITH & 8 & EARLY \\
\hline 13 & FEMALE & $<65$ & $\mathrm{NO}$ & 25 & NARROW & LONG & WITH & 8 & EARLY \\
\hline 13 & FEMALE & $<65$ & $\mathrm{NO}$ & 26 & NARROW & LONG & WITH & 8 & EARLY \\
\hline 14 & FEMALE & $\geq 65$ & $\mathrm{NO}$ & 23 & REGULAR & LONG & WITH & 3 & EARLY \\
\hline 14 & FEMALE & $\geq 65$ & $\mathrm{NO}$ & 45 & REGULAR & LONG & WITHOUT & 5 & EARLY \\
\hline 15 & MALE & $<65$ & $\mathrm{NO}$ & 36 & REGULAR & SHORT & WITHOUT & 5 & EARLY \\
\hline 16 & FEMALE & $<65$ & $\mathrm{NO}$ & 26 & REGULAR & SHORT & WITH & 10 & LATE \\
\hline 17 & MALE & $<65$ & $\mathrm{NO}$ & 11 & REGULAR & LONG & WITHOUT & 4 & LATE \\
\hline 18 & FEMALE & $<65$ & NO & 26 & REGULAR & SHORT & WITHOUT & 4 & LATE \\
\hline
\end{tabular}




\section{Discussion}

In the present study, GEE analyses were used for the evaluation of dental implant outcomes and identification of risk factors associated with implant failure. Demographic, anatomic, and implant-related variables were collected, and ancillary procedures were performed in a large sample of patients attending an educational institution. The risk factors for implant failure were found to be maxillary sites and bone augmentation. Investigators using the most common statistical methods to evaluate risk factors in dental literature fail to assume that eventually, several implants are correlated as a result of being from the same patient. These results should not be treated as independent observations..$^{16}$ For this reason, an alternative strategy to achieve reliable statistical results in risk factor assessment is to select GEE to perform the analysis and to avoid the cluster effect.

Analysis of our clinical data demonstrated high CSRs of $96.8 \%$ and $91.8 \%$ for implant- and patient-based analyses, respectively. Previously published reports on implant CSRs show rates above $90 \%$. ${ }^{17,18}$ The success of dental implants has been attributed to several factors that have been well documented in the literature. ${ }^{19}$ Using both univariate and multivariate analyses, French et al. ${ }^{9}$ have shown CSRs of more than $98 \%$ at the implant level and more than $95 \%$ at the patient level, corroborating our results.

It is important to highlight that the association between systemic disorders and implant failures was analyzed, but the number of patients with these disorders was small, and no association was observed. Although the assessed dental records of patients were standardized and the students were trained to complete them as accurately as possible, data on previous and some present diseases depended on patient self-report. It is likely that several patients could not clearly remember details about their systemic health conditions, a limitation commonly observed in retrospective studies. ${ }^{15}$ In addition, the association between tobacco use and implant failure was not analyzed. In Brazil, the quitting rate is increasing, thus suggesting that tobacco control interventions implemented in previous years have effectively reached the smoking population. ${ }^{20}$ For this reason, the number of smokers included in the study was low, and tobacco smoking did not have an impact on the present analysis. However, several previous studies have demonstrated that smoking reduces the success rate of osseointegration and may be considered to be a risk factor for implant loss. ${ }^{11,21}$ Zupnik et al. could not find an association between implant failure and smoking, demonstrating a lower OR as well as a p-value of $<0.05 .^{19}$

Similarly, many studies have reported maxillary implant placement as a risk factor. ${ }^{11,22,23}$ Analysis of our data supports the finding that maxillary sites are more prone to implant failure than mandibular sites $(p=0.014)$. According to Noda et al., ${ }^{11}$, insufficient density of the maxillary bone may explain this finding. In addition, low bone density at implant locations has been previously described to be influential on implant failure. ${ }^{5,24}$ Using GEE analyses, Chrcanovic et al. ${ }^{25}$ have likewise found most implant failures in type IV bone.

Significantly more early implant failures for both mandibular and maxillary areas in posterior regions have been observed, according to several reports. 16,26,27,28,29 This may be attributable to a combination of multiple preconditions often present in posterior sites, such as barely sufficient bone volume, poor bonequality, and high functional forces. ${ }^{30}$ The cortical layer of both jaws tends to become thinner and more porous posteriorly. Moreover, posterior implants must withstand the heaviest load and are generally short due to the insufficient quantity of available bone (the maxillary sinus and inferior alveolar nerve are the main anatomical limitations). However, there is no consensus in the literature, and other available studies reporting contradictory findings have not considered maxillary sites or posterior implant placement as risk factors. ${ }^{31,32}$

It is important to emphasize that in our study, a trend toward bone augmentation as a risk factor for implant failure was detected (Table 2). However, a statistically significant association between implant failure and bone augmentation was not found in the present study, although other studies have demonstrated more failures in these sites..$^{33}$ Tonetti et al..$^{34}$ have highlighted that bone augmentation may present complications inherent to the implant technique and that implants placed in these areas do not present high long-term survival rates as those placed in natural bone areas.

To avoid augmentation, short and narrow implants are readily available, demonstrating favorable results. 
Many clinical ${ }^{35,36}$ and biomechanical ${ }^{15}$ studies have shown that the predictability of short implants is comparable with that of implants of normal length. In the present study, the success rate of short implants was found to be statistically the same as that of longer implants, as reported in another published assessment. ${ }^{37}$

Considering the limitations of this retrospective study design, the number of remaining teeth, opposing dentition characteristics, peri-implant vertical bone loss, and prosthesis variables such as restorations and loadings were not evaluated. In addition, there was no consideration of some possibly misleading factors such as patients' oral hygiene habits, alcohol intake, or periodontal status. ${ }^{37}$

The ability to predict an individual's risk of implant failure would be a significant advancement for the implant dentistry field. In contrast, it is interesting to analyze the success rates of dental implants placed by postgraduate students. Finally,

\section{References}

1. Hämmerle $\mathrm{CH}$, Ungerer MC, Fantoni PC, Brägger $U$, Bürgin W, Lang NP. Long-term analysis of biologic and technical aspects of fixed partial dentures with cantilevers. Int J Prosthodont. 2000;13(5):409-15.

2. Pjetursson BE, Tan $K$, Lang NP, Brägger $U$, Egger $M$, Zwahlen $M$. A systematic review of the survival and complication rates of fixed partial dentures (FPDs) after an observation period of at least 5 years IV. Clin Oral Implants Res. 2004;15(6):667-76. https://doi.org/10.1111/j.1600-0501.2004.01120.x

3. Hämmerle CHF, Glauser R. Clinical evaluation of dental implant treatment. Periodontol 2000. 2004;34(1):230-9. https://doi.org/10.1046/i.0906-6713.2003.003434.x

4. Buser D, Broggini N, Wieland M, Schenk RK, Denzer AJ, Cochran DL et al. Enhanced bone apposition to a chemically modified SLA titanium surface. J Dent Res. 2004;83(7):529-33. https://doi.org/10.1177/154405910408300704

5. Renouard F, Nisand D. Impact of implant length and diameter on survival rates. Clin Oral Implants Res. 2006;17(Suppl 2):35-51. https://doi.org/10.1111/j.1600-0501.2006.01349.x

6. Ganeles J, Zöllner A, Jackowski J, ten Bruggenkate C, Beagle J, Guerra F. Immediate and early loading of Straumann implants with a chemically modified surface (SLActive) in the posterior mandible and maxilla: 1 -year results from a prospective multicenter study. Clin Oral Implants Res. 2008;19(11):1119-28. https://doi.org/10.1111/j.1600-0501.2008.01626.x it is important to investigate how educational institutions could be more effective in providing learning opportunities to dentists and successfully treating this patient population.

\section{Conclusion}

In the assessment of dental implant outcomes in an educational institution, the implant- and patient-based CSRs were $96.8 \%$ and $91.8 \%$, respectively. Risk factors for implant failure using GEE analyses included implants placed in the maxillary arch as well as a strong trend toward bone augmentation areas.

\section{Acknowledgment}

The authors thank Prof. Dr. Ronir Raggio Luiz, Associate Professor, School of Epidemiology and Statistics, Institute of Public Health Studies, Federal University of Rio de Janeiro.
7. Peñarrocha-Diago $M$, Demarchi $C L$, Maestre-Ferrín L, Carrillo C, Peñarrocha-Oltra D, Peñarrocha-Diago MA.

A retrospective comparison of 1,022 implants: immediate versus nonimmediate. Int J Oral Maxillofac Implants. 2012;27(2):421-7.

8. Jung RE, Fenner N, Hämmerle CHF, Zitzmann NU. Long-term outcome of implants placed with guided bone regeneration (GBR) using resorbable and non-resorbable membranes after 12-14 years. Clin Oral Implants Res. 2013;24(10):1065-73. https://doi.org/10.1111/j.1600-0501.2012.02522.x

9. French D, Lariava H, Ofec R. Retrospective cohort study of 4591 Straumann implants in private practice setting, with up to 10 -year follow-up. Part 1: multivariate survival analysis. Clin Oral Implants Res. 2015;26(11):1345-54. https://doi.org/10.1111/clr.12463

10. Becker ST, Beck-Broichsitter BE, Rossmann CM, Behrens E, Jochens $A$, Wiltfang J. Long-term survival of straumann dental implants with TPS surfaces: a retrospective study with a follow-up of 12 to 23 years. Clin Implant Dent Relat Res. 2016;18(3):480-8. https://doi.org/10.1111/cid.12334

11. Noda K, Arakawa H, Kimura-Ono A, Yamazaki S, Hara ES, Sonoyama $\mathrm{W}$ et al. A longitudinal retrospective study of the analysis of the risk factors of implant failure by the application of generalized estimating equations. J Prosthodont Res. 2015;59(3):178-84. https://doi.org/10.1016/i.jpor.2015.04.003

12. Shintani A. Primer of statistics in dental research: part II. J Prosthodont Res. 2014;58(2):85-91. https://doi.org/10.1016/i.jpor.2014.03.003 
13. Shintani A. Primer of statistics in dental research: part I. J Prosthodont Res. 2014;58(1):11-6. https://doi.org/10.1016/i.jpor.2013.12.006

14. United Nations, Division for Social Policy and Develpment Ageing. Internatinal plan of action on aging and other resolutions and decisions of the World Assembly. In: Report of the World Assembly on Aging; 1982 July 26-Aug 12; Vienna, Austria. p. 46

15. Anitua $E$, Orive G. Short implants in maxillae and mandibles: a retrospective study with 1 to 8 years of follow-up. J Periodontol. 2010;;81(6):819-26. https://doi.org/10.1902/jop.2010.090637

16. Chuang SK, Wei LJ, Douglass CW, Dodson TB. Risk factors for dental implant failure: a strategy for the analysis of clustered failure-time observations. J Dent Res. 2002;81(8):572-7. https://doi.org/10.1177/154405910208100814

17. Lekholm U, Gunne J, Henry P, Higuchi K, Lindén U, Bergström C, van Steenberghe D. Survival of the Brånemark implant in partially edentulous jaws: a 10-year prospective multicenter study. Int J Oral Maxillofac Implants. 1999;14(5):639-45.

18. Buser D, Mericske-Stern R, Bernard JP, Behneke A, Behneke N, Hirt HP et al. Long-term evaluation of non-submerged ITI implants. Part 1: 8-year life table analysis of a prospective multi-center study with 2359 implants. Clin Oral Implants Res. 1997;8(3):161-72. https://doi.org/10.1034/j.1600-0501.1997.080302.x

19. Zupnik J, Kim SW, Ravens D, Karimbux N, Guze K. Factors associated with dental implant survival: a 4 -year retrospective analysis. J Periodontol. 2011;82(10):1390-5. https://doi.org/10.1902/jop.2011.100685

20. Szklo AS, Souza MC, Szklo M, Almeida LM. Smokers in Brazil: who are they? Tob Control. 2016;25(5):564-70. https://doi.org/10.1136/tobaccocontrol-2015-052324

21. Chen H, Liu N, Xu X, Qu X, Lu E. Smoking, radiotherapy, diabetes and osteoporosis as risk factors for dental implant failure: a meta-analysis. PLoS One. 2013;8(8):e71955. https://doi.org/10.1371/journal.pone.0071955

22. Carr AB. Implant location and radiotherapy are the only factors linked to 2-year implant failure. J Evid Based Dent Pract. 2012;12(3 Suppl):217-9. https://doi.org/10.1016/S1532-3382(12)70042-8

23. Wennström J, Zurdo J, Karlsson S, Ekestubbe A, Gröndahl K, Lindhe J. Bone level change at implant-supported fixed partial dentures with and without cantilever extension after 5 years in function. J Clin Periodontol. 2004;31(12):1077-83. https://doi.org/10.1111/j.1600-051X.2004.00603.x

24. Nedir R, Bischof M, Briaux JM, Beyer S, Szmukler-Moncler S, Bernard JP. A 7-year life table analysis from a prospective study on ITI implants with special emphasis on the use of short implants: results from a private practice. Clin Oral Implants Res. 2004;15(2):150-7. https://doi.org/10.1111/i.1600-0501.2004.00978.x

25. Chrcanovic BR, Kisch J, Albrektsson T, Wennerberg A. Factors influencing early dental implant failures. J Dent Res. 2016;95(9):995-1002. https://doi.org/10.1177/0022034516646098
26. Sánchez-Garcés MA, Costa-Berenguer $X$, Gay-Escoda C. Short implants: a descriptive study of 273 implants. Clin Implant Dent Relat Res. 2012;14(4):508-16. https://doi.org/10.1111/j.1708-8208.2010.00301.x

27. Degidi $M$, lezzi $G$, Perrotti $V$, Piattelli A. Comparative analysis of immediate functional loading and immediate nonfunctional loading to traditional healing periods: a 5 -year follow-up of 550 dental implants. Clin Implant Dent Relat Res. 2009;11(4):257-66. https://doi.org/10.1111/j.1708-8208.2008.00117.x

28. Jaffin RA, Berman CL. The excessive loss of Branemark fixtures in type IV bone: a 5-year analysis. J Periodontol. 1991;62(1):2-4. https://doi.org/10.1902/jop.1991.62.1.2

29. Alsaadi $G$, Quirynen $M$, Komárek $A$, van Steenberghe D. Impact of local and systemic factors on the incidence of oral implant failures, up to abutment connection. J Clin Periodontol. 2007;34(7):610-7. https://doi.org/10.1111/j.1600-051X.2007.01077.x

30. Glauser R, Rée A, Lundgren A, Gottlow J, Hämmerle CH, Schärer P. Immediate occlusal loading of Brånemark implants applied in various jawbone regions: a prospective, 1-year clinical study. Clin Implant Dent Relat Res. 2001;3(4):204-13. https://doi.org/10.1111/j.1708-8208.2001.tb00142.x

31. Chung DM, Oh TJ, Lee J, Misch CE, Wang HL. Factors affecting late implant bone loss: a retrospective analysis. Int J Oral Maxillofac Implants. 2007;22(1):117-26.

32. Schrott A, Riggi-Heiniger M, Maruo K, Gallucci GO. Implant loading protocols for partially edentulous patients with extended edentulous sites: systematic review and meta-analysis. Int J Oral Maxillofac Implants. 2014;29 Suppl:239-55. https://doi.org/10.11607/jomi.2014suppl.g4.2

33. Tran DT, Gay IC, Diaz-Rodriguez J, Parthasarathy K, Weltman R, Friedman L. Survival of dental implants placed in grafted and nongrafted bone: a retrospective study in a university setting. Int J Oral Maxillofac Implants. 2016;31(2):310-7. https://doi.org/10.11607/jomi.4681

34. Tonetti MS, Hämmerle CHF. Advances in bone augmentation to enable dental implant placement: Consensus Report of the Sixth European Workshop on Periodontology. J Clin Periodontol. 2008;35(8 Suppl):168-72. https://doi.org/10.1111/j.1600-051X.2008.01268.x

35. Goené R, Bianchesi C, Hüerzeler M, Del Lupo R, Testori T, Davarpanah $M$ et al. Performance of short implants in partial restorations: 3-year follow-up of Osseotite implants. Implant Dent. 2005;14(3):274-80. https://doi.org/10.1097/01.id.0000173335.90854.d8

36. Renouard F, Nisand D. Short implants in the severely resorbed maxilla: a 2-year retrospective clinical study. Clin Implant Dent Relat Res. 2005;7(Suppl 1):S104-10. https://doi.org/10.1111/j.1708-8208.2005.tb00082.x

37. Lai HC, Si MS, Zhuang LF, Shen H, Liu YL, Wismeijer D. Long-term outcomes of short dental implants supporting single crowns in posterior region: a clinical retrospective study of 5-10 years. Clin Oral Implants Res. 2013;24(2):230-7. https://doi.org/10.1111/j.1600-0501.2012.02452.x 